\title{
Terrorism Threat in Doctrine Formulating of Military Campaign Scenario to Achieve National Security
}

\section{On Estimative Methodology Review}

\author{
Novky Asmoro ${ }^{1}$, Pujo Widodo ${ }^{2}$, Resmanto Widodo Putro ${ }^{2}$, Cecep Hidayat ${ }^{1} \&$ Rizki Putri $^{3}$ \\ ${ }^{1}$ Student of Doctoral Program in Defense Science, Republic of Indonesia Defense University, Bogor, Indonesia \\ ${ }^{2}$ Lecturer of Doctoral Program in Defense Science, Republic of Indonesia Defense University, Bogor, Indonesia \\ ${ }^{3}$ Master of Defense Economics of Republic of Indonesia Defense University, Bogor, Indonesia \\ Correspondence: Novky Asmoro, State Universities in the field of Defense Studies which provides education for \\ Undergraduate, Masters, and Doctoral Degress, Indonesia.
}

Received: June 26, 2021; Accepted: August 8, 2021; Published: August 14, 2021

\begin{abstract}
Based on the estimation methodology on the potential of the war against terrorism on the transformation of doctrine, the conclusions based on the predictive analysis are: (1) The potential for the war against terrorism has a very strong relevance to the prediction of changes in military campaign doctrine in the long term by producing new war strategies both in terms of ends-means-ways as a result of High Impact Low Probability, (2) Through predictive analysis with extrapolation model, it is found that threats, strategic environment and tradition or history are variables that are expected to remain unchanged, especially in the short term in influencing the preparation of Military Campaign Doctrine, (3) The Projection Model determines if Threat is the variable that changes the most so that it will affect changes in the Military Campaign Doctrine in the short to medium term, (4) Looking for the best solution in realizing the best Military Campaign Doctrine. This can be followed by designing a simulation of the New War Strategy as a result of forecasting the Military Campaign Doctrine.
\end{abstract}

Keywords: Doctrine, Military Campaign, National Security, Estimative Methodology

\section{Introduction}

The threat of terrorism is a hybrid threat that uses a combination of military and non-military methods in peacetime to achieve traditional military objectives and to conquest of the certain territorials and thereby changing the "facts on the ground" without triggering actual conflict. According to Michael Mazarr, from the National War College (2019) revealed that the war on peacetime terrorism aims to achieve military goals, namely battlefield control. It emphasizes the linearity between terrorism and the threat of Terrorism that "the goal of the war on Terrorism is to win a conclusive campaign through the use of force and some degree of violence, or to prepare some kind of decisive military action."

The threat of terrorism is also mentioned as another concept of hybrid warfare as explained in Ministry of Defense Regulation number 19 of year 2015 regarding the Policy for the Implementation of National Defense namely that this form of war combines conventional war or threats, asymmetric, terrorist and cyber warfare, as well as diverse and dynamic criminals. In addition to these various combinations of threats, the war on terrorism can also take the form of an integrated attack between the use of Chemical, Biological, Radiological, Nuclear and Explosive (CBRNE), and information warfare.

The government's seriousness in managing the country's defense and security is not only projected to face external enemies but also, prepare for the possibility of developing the problem of terrorism in the country. The purchase of Indonesian Armed Forces (TNI) weapons equipment in the last three years is also prepared for the possibility of facing the war. TNI readiness to face the threat of terrorism is a military strategy that combines conventional war, irregular war and terror threats, including further terror motives by utilizing social media, information to nuclear attacks, biological and chemical weapons, improvised explosive devices and information warfare. Faced with modern war doctrine and a complex spectrum of threats, it is deemed necessary if the Military Campaign as part of War Military Operations is time to transform with strategic objectives, one of which is the ability to deal with the threat of terrorism. As a basis for thinking and acting, of course, the Military Campaign must be based on a doctrine 
that can be adaptive to changing times and the mission objectives to be achieved, including in overcoming the threat of terrorism. In the future, the Military Campaign doctrine needs to be able to accommodate the way of acting in joint TNI operations to be deployed when facing threats in the category of terrorism threats.

In order to predict the trend of the threat of terrorism, it is necessary to have the role of intelligence that will comprehensively analyze how relevant it will be in the future, so it is necessary to prepare an increasingly adaptive doctrine. The intelligence analysis process requires a special method known as Estimative Methodology where the predictive analysis presented regardless of the configuration will be able to accurately predict several key variables to be presented through several levels of analysis to customers as decision making material.

\section{Political Situation Issue Decomposition}

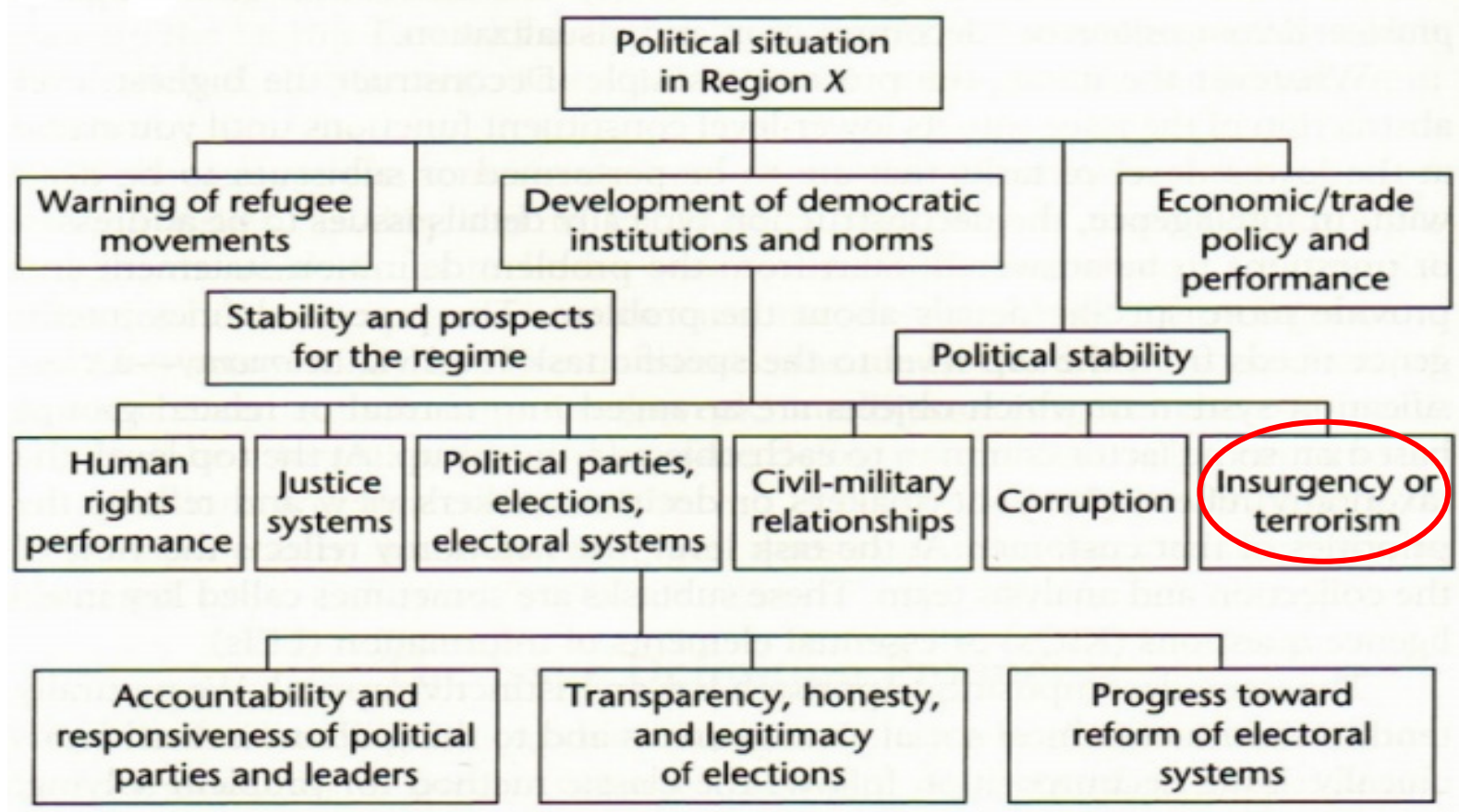

Figure 1. Tren Isu Politik Dunia

Source: Clark (2019). Intelligence Analysis

Efforts to carry out predictive analysis of potential threats of terrorism in the future are important because terrorism itself has been classified as a Political Situation Issue Decomposition as one of the trends in world strategic political issues. The picture above describes that the threat of terrorism is included in the strategic intelligence issue whose data continues to be explored. This is relevant to the development of the main characteristics of the role of modern intelligence, namely:

a. Analysis can take many forms by utilizing multiple sources in an effort to obtain more complete data and information. Some of the sources include special expertise from the academic, social media, or industrial domains.

b. Analysis of any subject is an ongoing process. Customers are increasingly in need of intelligence support on a daily basis regarding several issues, both general and specific.

\section{Methodology}

Prediction in an intelligence product is a crucial thing needed by decision makers (Coker, 2014). Through the use of Estimative Methodology, various predictive analysis processes are carried out in order to obtain high validity and reliability of information so as to achieve a reliable level of analysis so that predictions on the future condition of an intelligence object can be estimated. Different estimation methods are used in different conditions. Several models of estimative methodology, one of which is applied to military intelligence through a predictive analysis process, include (Clark, 2019).

a. Extrapolation Models. This prediction method is the most conservative method and is suitable for short-term 
estimation. In its simplest form, extrapolation, using historical performance as a basis, to indicate future directions. (Determining the estimated object variable extrapolated to the future without changing the variable).

b. Projection Models. In this model, it is done by predicting various possible futures based on the assumption that the forces that have prevailed in the past will change, while extrapolation assumes that the forces do not change (Determining one variable that is considered the most dominant or most influential in the future).

c. Model Forecasting (Forecasting). The prediction model in this intelligence activity is to determine the alternative future of the target, not just the most likely future. However, being able to formulate long-term alternatives and scenarios that are most likely to occur in the future (Determining new variables outside of existing variables but still having relevance among them).

d. Of the three forecasting models that lead to the emergence of new variables when forecasting is carried out, the next step is to determine which of these variables has the greatest effect but has a low probability of occurrence (High Impact Low Probability). The result of High Impact Low Probability (HILP) is a Demonstration Scenario and the process to determine HILP is carried out through the following stages:

1) Determining the variables that are considered to have the most significant impact on the outcome because this will be analyzed continuously.

2) Develop a logical description of the analysis of several variables or forces that are expected to have the least impact. This is important in determining the indicators that need to be monitored during the predictive analysis process.

3) Determine the single most significant factor that can trigger a sudden and comprehensive change to the object of analysis.

4) Carry out a brainstorming process regarding the breadth of experience of each intelligence agent in an effort to find the most likely strengths or variables, which are unpredictable but can change the entire analysis result suddenly.

5) Always carry out monitoring of the indicators that have been determined to prevent them from getting out of the way of analysis.

6) Identify all of the estimated factors that will either lead to good or bad outcomes.

\section{The Estimative Methodology}

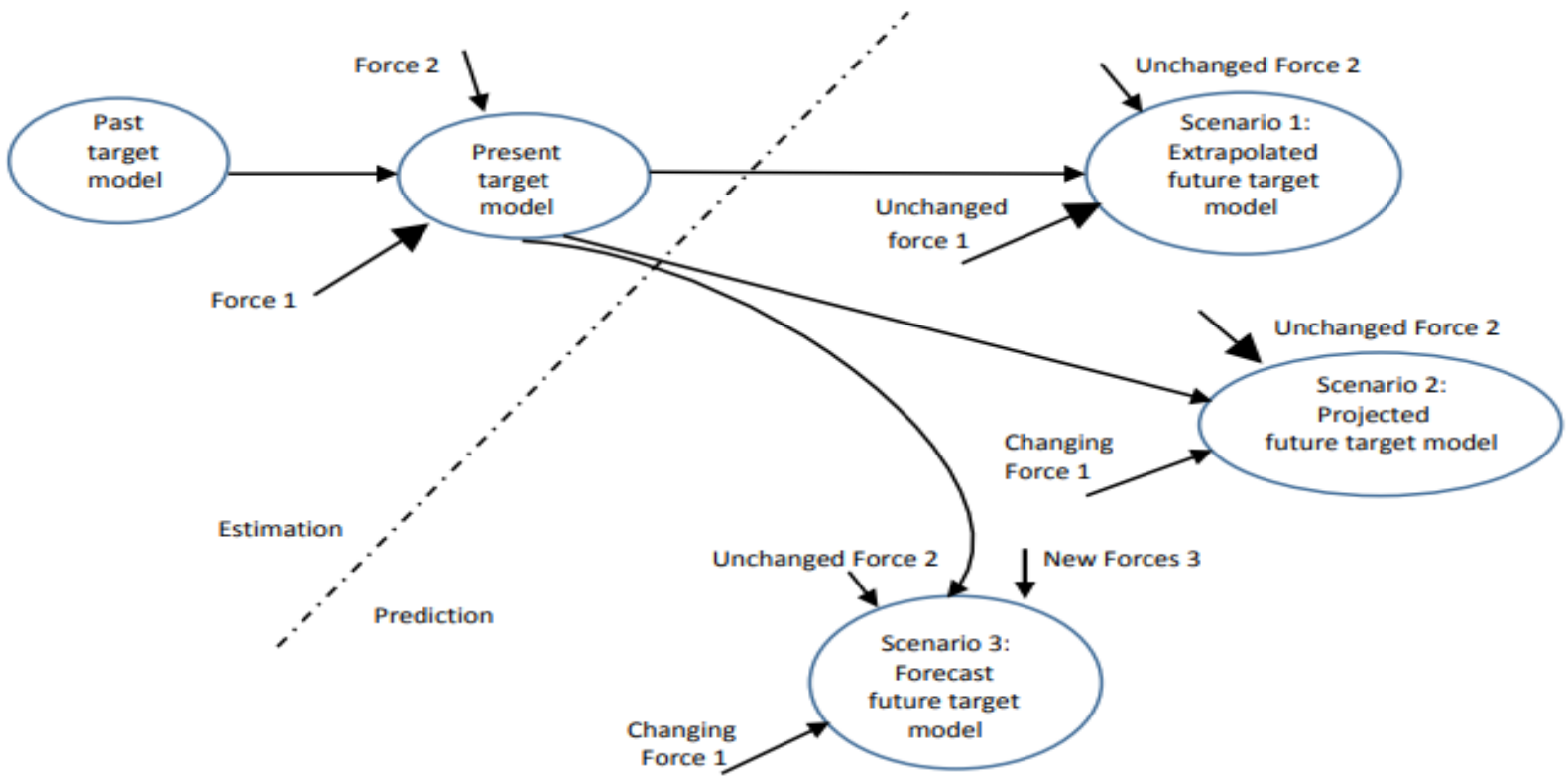

Figure 2. Illustration of Estimative Methodology

Source: Clark (2019), Intelligence Analysis

Determining an estimate for future global conditions can be done by studying the strategic environment in the military, political and economic as well as social aspects which tend to change rapidly. These problems have a 
strength component that can be identified using variants of the strategy methodology. Forecasts of changes in these forces are analyzed through trends and the resulting events then between one event/trend are linked together through techniques such as cross-impact analysis. The result is a "most likely" future forecast made in a scenario format. If the forecasts made work well, it will encourage policy makers to make decisions and for the intelligence world, will result in action in response to real and unreal threats.

In order to get valid and reliable prediction results, several processes are carried out, including brainstorming. This step is very important in determining the six main questions on the object of estimation or called the Six-pointed Star which includes "Who, What, When, Where, Why and How". (Hart, 2012). In addition, through the brainstorming stage, it will be possible to determine the key assumption check stage, which is a hypothesis that has been declared true and is part of defining the problem or as a product of the final assessment.

\section{Result}

The existence of the threat of terrorism can be understood as part of a hybrid war that combines military and nonmilitary threats that occur in peacetime to achieve the goal of the threat in the form of the results of traditional military warfare, for example territorial control or conquest. The threat of terrorism in principle can achieve the objectives of conventional war without triggering actual conflict. Therefore, being faced with modern war doctrine and a complex spectrum of threats is necessary if the Military Campaign as part of War Military Operations is time to transform with strategic objectives, one of which is the ability to deal with the threat of terrorism (Anderson, 1998).

As a basis for thinking and acting, of course, the Military Campaign must be based on a doctrine that can be adaptive to the mission objectives to be achieved, including overcoming the threat of terrorism. In the future, the Military Campaign doctrine needs to be able to accommodate the way of acting in joint TNI operations to be deployed when facing threats in the category of terrorism threats. Therefore, it is necessary to make an effort or implement predictive analysis in order to determine the form of the military campaign doctrine in the future based on several variables that will be determined next.

In carrying out Predictive Analysis, it is necessary to carry out several stages which will later be processed through several predictive analysis models, both extrapolation, projection and Forecast (Forecasting). The steps taken based on the research focus are the Dynamics of the Threat of Terrorism to the Transformation of the Doctrine of the Indonesian Military Campaign to Realize National Security, namely:

a. Determining a condition of an entity whose existence can be predicted based on past conditions to the future. The entity that is focused here is the Military Campaign Doctrine.

b. Determine the forces or several factors that affect the existence of the entity which in this case is the Military Campaign Doctrine. The forces or factors that influence it are the Threat Spectrum, the Dynamics of the Strategic Environment, and the Tradition or History of the Nation's Struggle (Thomas Aquinas and Hugo Grotius, 1631). These three factors will be used as variables that are fixed / will not change in the future even though their value will increase or decrease as an Extrapolation Model.

c. In the three forces or factors, one factor is determined which is predicted to have the most dominant influence or experience the highest dynamics. It will be used predictive analysis with the Projection Model in this case is the Threat Spectrum.

\begin{tabular}{|l|c|c|c|}
\hline \multicolumn{1}{|c|}{$\begin{array}{c}\text { Variable/ } \\
\text { Model of Predictive Analysis }\end{array}$} & Extrapolation & Projection & Forecasting \\
\hline Threat & Steady & Dominant & None \\
\hline Strategic Environment & Steady & Steady & None \\
\hline History & Steady & Steady & None \\
\hline War Strategy & None & None & Dominant (HILP) \\
\hline
\end{tabular}

Figure 3. Variable Matrix of Military Campaign Doctrine vs Model Predictive Analysis

Source: Clark (2019), Intelligence Analysis, processed

d. Starting from the extrapolation and projection models, a new force or factor is determined which is predicted to emerge as a new force that can occur or directly impact the Military Campaign Doctrine entity and this 
model is referred to as the Forecast Model. The forces that are estimated to appear are New War Strategies. The relationship between the variables and the predictive model of analysis can be seen in Figure 3 .

e. Determine predictions of the future state of the Military Campaign Doctrine as an entity or model target based on the assessment of each force. Each strength will be measured or weighed based on its weight. The dominant strength will be measured in this prediction through several estimation tools, including Regression and Monte Carlo Simulation.

\section{Discussion}

Based on the results of the predictive analysis above, it is found that from the three fixed variables used for extrapolation, one dominant variable will be obtained, namely Threat as a result of the projection. This indicates that the Military Campaign Doctrine in the future must be adaptive to the dynamics of threats that occur where the threat of terrorism is included. So it is appropriate if the potential threat of terrorism needs to be predicted in the future so that the doctrine that is prepared is in accordance with the needs of military operations.

Specifically also obtained prediction results with forecasting that War Strategy will turn out to be a new variable that appears and is in accordance with the rules of predictive analysis, so this is an indication that for the future war strategy will continue to transform even though the possibility is small but the effect is very large (High Implact Low Probability ). This condition is very relevant because the battle strategy if predicted will not change much from the classical theory of strategy which states that "a coherent expression of a process that identifies the ends, ways, and means designed to achieve a certain goal. Mathematically, we might express this as "Strategy = Ends + Ways + Means." Ends are the objectives or desired outcomes of a given strategy. The term end-state is synonymous with ends. An end or ends comprises the goal of the strategy. Ways are actions". (Lykke, 1998)

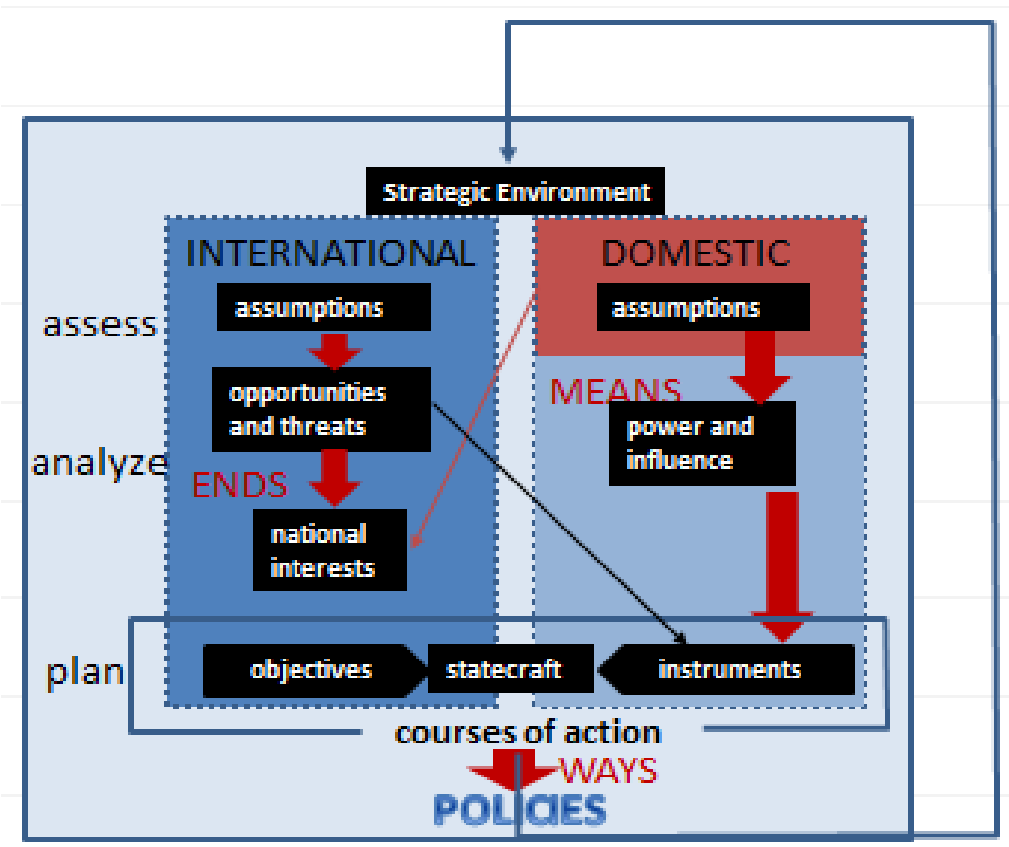

Figure 4. Theoretical Implementation of Strategy

Source: Deibel (2007), Foreign Affair Strategies

The next step after successfully determining a new variable from the forecasting model which is a variable with a High Impact Low Probability character, is to design a Demonstration Scenario. The scenario, which is the product of the High Impact Low Probability analysis, can be generated if an intelligence analyst is able to identify the High Impact Outcome and then determine a logical way to achieve it. There are several ways to get High Impact Outcome, one of them is by using an alternative version of the Demonstration Scenario, namely Branch-point Scenario.

The main function of the demonstration scenario is to pay more attention to the results of the analysis of the branchpoint scenario than the final results of the analysis. So the new War Strategy as HILP, for an intelligence analyst 
will not focus on the War Strategy, but rather on how to realize the new war strategy because it has the greatest impact even though it is unlikely to have an effect on the military campaign doctrine that will later faced with the war against terrorism. The stages in getting the best scenario in determining the best Military Campaign Doctrine generally follow the following phases are

a. Determining the Problem. This leads to "What question will the new Military Campaign Doctrine actually answer?

b. Identify what factors will influence the preparation of the Military Campaign Doctrine. In this phase, intelligence analysis will determine the main factors and priorities in the preparation of the Military Campaign Doctrine.

c. Identify the most feasible solution to implement. In principle, there are several more scenarios in it, namely: Emergency Scenario (Created by positioning intelligence analysts as opponents), What-if Scenario unlimited (unconstrained) and What-if Scenario limited (constrained).

d. Looking for the best solution in realizing the best Military Campaign Doctrine. This can be followed by designing a simulation of the New War Strategy as a result of forecasting the Military Campaign Doctrine.

\section{Conclusion}

Based on the estimation methodology on the potential of the war against terrorism on the transformation of doctrine, the conclusions based on the predictive analysis are:

a. The potential for the war against terrorism has a very strong relevance to the prediction of changes in military campaign doctrine in the long term by producing new war strategies both in terms of ends-means-ways as a result of High Impact Low Probability.

b. Through predictive analysis with extrapolation model, it is found that threats, strategic environment and tradition or history are variables that are expected to remain unchanged, especially in the short term in influencing the preparation of Military Campaign Doctrine.

c. The Projection Model determines if Threat is the variable that changes the most so that it will affect changes in the Military Campaign Doctrine in the short to medium term.

d. If war strategy is indeed determined as HILP in changing the formulation of military campaign doctrine, then to realize effective anticipatory measures, a comprehensive simulation is needed so that the resulting doctrine will be adaptive to changes in threats, strategic environment, traditions or history and future war strategies.

\section{Acknowledgement}

The author appreciates the insights from lecturers and colleagues and peers at Republic of Indonesia Defense University (RIDU). Valuable resources accessible at the Doctoral Study Program of Defense Sciences dan Library of RIDU also strengthen the author's determination to write this article. However the views expressed in this article are the author's (except otherwise specified) and do not reflect the official stance Ministry of Defence of the Republic of Indonesia and RIDU. The author also would like to thank the referees for their comments.

\section{References}

Coker, F. (2014). Pulse: Understanding the Vital Signs of Your Business, Bellevue, WA: Ambient Light Publishing.

Clark, R. M. (2019). Intelligence Analysis, A-Target Centric Approach, CQ Press.

Deibel, Terry L (2014). Foreign Affairs Strategy Logic for American Statecraft, Cambridge University Press Hart, G. (2012). The Five Ws of Online Help, TECHWR-L.

Kementerian, P. R. I. (2015). Peraturan Menteri Pertahanan No.19 Tahun 2015 Tentang Kebijakan Penyelenggaraan Pertahanan Negara Tahun 2015-2019.

Lykke, Jr. A. F. (1998). Military Strategy: Theory and Application Carlisle, PA: U.S. Army War College.

Mazzar, M. (2019). Vikhrant Desphande. Hybrid Warfare: The Changing Character of Conflict, Institute for Defense Studies amd Analysis (IDSA).

Tulak, A. N. (2021). Perang Terorisme, Tantangan Baru dalam Lingkungan Informasi. Retrieved 22 April 2021, from https://ipdefenseforum.com

Walter, N. A. (1998) . Doktrin Gabungan AS, JP 3-0, Operasi Gabungan, US Army. 


\section{Copyrights}

Copyright for this article is retained by the author(s), with first publication rights granted to the journal.

This is an open-access article distributed under the terms and conditions of the Creative Commons Attribution license (http://creativecommons.org/licenses/by/4.0/). 